\title{
8
}
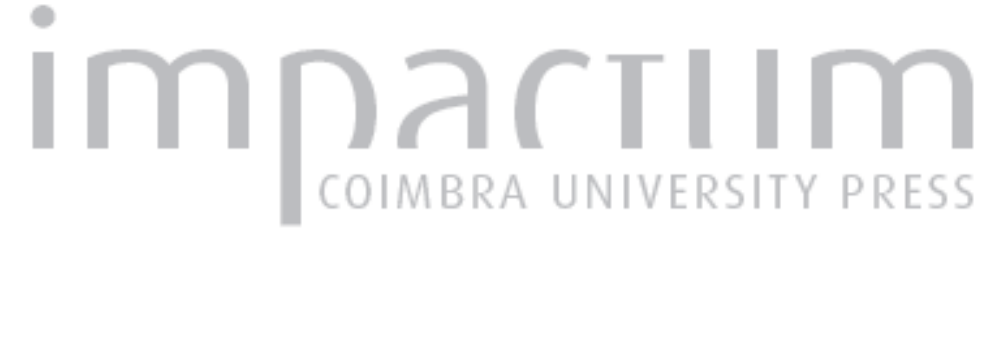

\section{A frequência do tema "tráfico de pessoas" em dissertações de mestrado e teses de doutoramento disponibilizadas no Estudo Geral da UC (2006-2016)} \author{
$\begin{array}{ll}\text { Autor(es): } & \text { Pinto, Rooney Figueiredo; Valente, Isabel Maria Freitas; Guia, Maria } \\ \text { João }\end{array}$
}

Publicado por: Imprensa da Universidade de Coimbra

URL

persistente:

URI:http://hdl.handle.net/10316.2/43063

DOI:

DOI:https://doi.org/10.14195/1647-6336_17_4

\section{Accessed : $\quad$ 26-Apr-2023 14:59:21}

A navegação consulta e descarregamento dos títulos inseridos nas Bibliotecas Digitais UC Digitalis, UC Pombalina e UC Impactum, pressupõem a aceitação plena e sem reservas dos Termos e Condições de Uso destas Bibliotecas Digitais, disponíveis em https://digitalis.uc.pt/pt-pt/termos.

Conforme exposto nos referidos Termos e Condições de Uso, o descarregamento de títulos de acesso restrito requer uma licença válida de autorização devendo o utilizador aceder ao(s) documento(s) a partir de um endereço de IP da instituição detentora da supramencionada licença.

Ao utilizador é apenas permitido o descarregamento para uso pessoal, pelo que o emprego do(s) título(s) descarregado(s) para outro fim, designadamente comercial, carece de autorização do respetivo autor ou editor da obra.

Na medida em que todas as obras da UC Digitalis se encontram protegidas pelo Código do Direito de Autor e Direitos Conexos e demais legislação aplicável, toda a cópia, parcial ou total, deste documento, nos casos em que é legalmente admitida, deverá conter ou fazer-se acompanhar por este aviso.

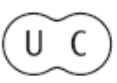




\section{DEBATER \\ A EUROPA}

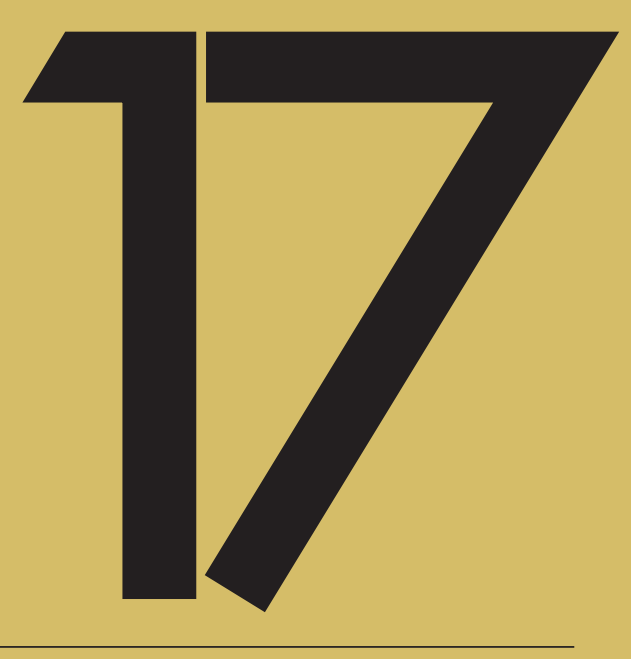

jul-dez 2017

UNIÃO EUROPEIA E O COMBATE AO
TRÁFICO DE SERES HUMANOS

THE EUROPEAN UNION AND COMBATING

TRAFFICKING IN HUMAN BEINGS 


\section{A frequência do tema "tráfico de pessoas" em dissertações de mestrado e teses de doutoramento disponibilizadas no Estudo Geral da UC (2006-2016) \\ The frequency of the subject "trafficking of people" in master's dissertations and doctoral thesis available in the "estudo geral da uc" (2006-2016)}

Rooney Figueiredo Pinto Doutorando - CEIS20-UC E-mail: rooneypinto@gmail.com

Isabel Maria Freitas Valente, $\mathrm{PhD}$ Investigadora CEIS20-UC E-mail: valente.isa@gmail.com

Maria João Guia, PhD Investigadora IJ-UC E-mail: maria.joao.guia@ij.uc.pt

\section{Resumo}

O Estudo Geral é o repositório digital da Universidade de Coimbra. Ligado ao SIBUC, permite uma maior visibilidade da produção científica da de seus investigadores. Este artigo tem por principal objetivo verificar a frequência do tema "Tráfico de Pessoas" em Dissertações de Mestrado e teses de Doutoramento depositadas no Estudo Geral entre 2006 e 2016. Assim, pretende responder às perguntas de investigação: 1. Qual a frequência do tema "Tráfico de Pessoas" em Dissertações de Mestrado e Teses de Doutoramento depositadas no Estudo Geral da UC entre 2006 e 2016?; 2. O que é possível inferir acerca do interesse científico pelo tema a partir das frequências de Dissertações de Mestrado e Teses de Doutoramento depositadas no Estudo Geral? Adotando uma abordagem quantitativa quanto ao tipo/método, explicativa quanto aos objetivos e descritiva quanto aos procedimentos, procedeu-se a pesquisa da frequência do tema tráfico de pessoas, em Dissertações de Mestrado e Teses de Doutoramento (2006-2016). Como resultado verificou-se um número reduzido de trabalhos, foram consultados o catálogo da BGUC e RCAAP, os quais também apresentaram poucos trabalhos, indicando um baixo interesse pelo tema. 
Palavras-Chave: Estudo Geral da UC; Tráfico de Pessoas enquanto tema central; Dissertações de Mestrado e Teses de Doutoramento.

\begin{abstract}
The "Estudo Geral" is the digital repository of the University of Coimbra. Part of SIBUC, it allows a greater visibility of the scientific production of and researchers. This article aims to verify the frequency of the subject "Trafficking of People" in Master's and Doctoral theses deposited in the "Estudo Geral" between 2006 and 2016. Thus, it intends to answer the research questions: 1 . How often is the subject "Traffic People "in Master's Dissertations and PhD Theses deposited in the Estudo Geral between 2006 and 2016 ?; 2. What can be inferred about the scientific interest in this subject from the frequencies of Master's Dissertations and PhD Thesis deposited in the Estudo Geral? Adopting a quantitative approach regarding the type/method, explanatory (objectives) and descriptive (procedures), the frequency of the subject of "trafficking of people" in Master Dissertations and Doctoral Theses (2006-2016). As a result, a small number of papers were found, the catalog of BGUC and RCAAP were consulted, which also presented few works, indicating a low interest in this subject.
\end{abstract}

Keywords: Estudo Geral da UC; Traffic of People as principal subject; Masters Dissertations and Doctorate Thesis.

\title{
Introdução
}

Este artigo foi escrito a partir da comunicação "Tráfico de pessoas enquanto tema central de teses e dissertações disponíveis no repositório digital da UC (2006-2016) - Entre a relevância do tema e o interesse acadêmico", apresentada no Colóquio "Dia Europeu Contra o Tráfico de Pessoas" em 18 de outubro de 2016 e organizado pelo Grupo de Investigação "Europeísmo, Atlanticidade e Mundialização" do Centro de Estudos Interdisciplinares do Século xx da Universidade de Coimbra (CEIS20-UC).

De forma a contextualizar a problemática que envolve este complexo tema, é importante lembrar que o tráfico de pessoas é um problema de possui raízes históricas e de abrangência global, hoje caracterizado como um crime transnacional e com impacto em diversas esferas da sociedade. A afirmação contemporânea é um esforço para nos lembrar que o passado escravagista onde o ser humano era tratado como um objeto capaz de gerar lucro aos seus proprietários não é uma realidade tão distante. Ironicamente, nossas escolas abordam o tema apenas do ponto de vista histórico, ignorando o facto de que este perigo bate à porta todos os dias, ou melhor, entra em nossas vidas pelos ecrãs todos os dias.

A exposição contínua aos mais diferentes flagelos sociais, tais como fome e miséria, crises económicas, guerras e doenças, talvez nos tenham conduzido a um certo nível de indiferença quanto à publicitação ou a notícia sobre os problemas dessa ordem. Uma ou 
outra vez, sentimos o choque social provocado por uma imagem, um filme, um documentário, uma notícia. Mas é preciso que seja demasiada forte, demasiada intensa, demasiada trágica, para que ocupe a atenção dos media e, somente posteriormente, ocupe a nossa atenção. O tráfico de pessoas transita entre a tragédia que nos choca e o esquecimento que nos consola, sendo expectável que nosso interesse pelo tema flutue consoante o grau de destaque que ele ocupa enquanto acontecimento no nosso cotidiano. É neste ponto que esta investigação toca ainda que na superfície, a relevância do tema. Propondo-se a investigar, através da frequência de trabalhos depositados no Estudo Geral da UC, o número de entradas relativas a Dissertações e Teses que possuem no título como tema central a problemática do tráfico de pessoas, no intervalo temporal compreendido entre 2006 e 2016. Partindo de uma leitura de que quanto maior o interesse por um tema, maior a produção científica em torno deste, elaboramos as seguintes perguntas de investigação: 1. Qual a frequência do tema "Tráfico de Pessoas" em Dissertações de Mestrado e Teses de Doutoramento depositadas no Estudo Geral da UC entre 2006 e 2016?; 2. O que é possível inferir acerca do interesse científico pelo tema a partir das frequências de Dissertações de Mestrado e Teses de Doutoramento depositadas no Estudo Geral?

O ambiente académico, nomeadamente dos cursos de Mestrado e Doutoramento, exige do estudante uma prática crítico-investigativa quanto aos fenómenos sociais que lhe cercam. De forma que é possível que ele, o estudante, sinta-se motivado a investigar um tema que lhe incomoda socialmente. Em conjunto com as motivações dos professores, das ferramentas disponíveis para suas pesquisas e da empatia científica com o tema, o jovem investigador desenvolve seu interesse em explorar este ou aquele objeto de estudo durante o desenvolvimento de sua Dissertação de Mestrado ou Tese de Doutoramento. Como todos os trabalhos de conclusão de curso (Dissertações de Mestrado e Teses de Doutoramento) devem ser depositados no Estudo Geral após a defesa, o repositório digital da UC funciona como um espelho de tendências, exibindo uma paleta de temas que foram escolhidos como objeto central das investigações.

Como pressupostos teóricos e contextualização da nossa investigação apresentamos três tópicos introdutórios os quais, em linhas gerais, discorrem sobre os "repositórios digitais" e o "tema do tráfico de pessoas". No primeiro tópico, "O protagonismo dos repositórios digitais no cenário académico", abordamos o papel dos repositórios digitais no armazenamento e promoção da produção científica, dos investigadores e das instituições. No segundo tópico, intitulado "Oportunidades e desafios na gestão de repositórios digitais", preferimos por dividir nossa exposição em dois sub-tópicos. O primeiro sub-tópico, "Ética e qualidade" apresenta uma reflexão sobre o desafio de gestão da imagem do repositório, a qual pode a todo momento ser abalada pelo depósito de um conteúdo de baixa qualidade ou mesmo resultado de fraude (plagio). No segundo sub-tópico, "Visibilidade e prática da obrigatoriedade como recurso de sobrevivência dos Repositórios Digitais", abordamos o paradoxo académico onde todos reconhecem a importância dos repositórios 
digitais para promoção dos trabalhos científicos, dos investigadores e, sobretudo, partilha de conhecimento, mas não estão motivados o suficiente para depositar suas investigações nestes mesmos repositórios. Com a cautela de não generalizar este comportamento, afirmando que todos os investigadores apresentam resistência em depositar seus trabalhos nos repositórios digitais, esperamos provocar uma reflexão quanto a este problema. Especialmente porque quando a produção científica está à disposição de outros investigadores, a partilha pode gerar críticas e melhorias na investigação já realizada. O último e talvez mais denso tópico introdutório está intitulado "A pertinência do tema tráfico de pessoas". Neste, apresentamos de forma muito resumida o tema do tráfico de pessoas enquanto problema social internacional, caracterizado juridicamente como crime transnacional e cujas dimensões dificultam em muito sua investigação. Sobre este ponto, destacamos o desafio que se coloca aos investigadores do tema, os quais precisam explorar o problema enquanto tema central, considerando seus inúmeros desdobramentos, mas policiando-se para não o condenar à periferia do estudo.

\section{O protagonismo dos repositórios digitais no cenário académico}

A evolução das plataformas de bibliotecas digitais assentadas em sistemas DL (Digital Library) continua em curso com implantação contínua numa escala global em diversas instituições, especialmente em universidades. Diante deste cenário, uma das consequências naturais é a popularização das Bibliotecas Digitais nas instituições, as quais terminam por implantar seus próprios sistemas DL com adaptações que atendem às necessidades de seus públicos internos e externos, tornando seus repositórios mais efetivos e eficientes (Chen \& Zhang, 2014, p. 559).

A inclusão de ferramentas digitais nos contextos de registo, proteção, gestão e partilha de produção científica não somente cumpre o papel social de democratização do conhecimento, como igualmente promove uma maior visibilidade dos centros de investigação vinculados às Faculdades e Universidades. A UC Impactum está assentada no sistema Open Journal Systems (OJS) do Public Knowledge Project (PKP)', reconhecidamente um dos mais utilizados sistemas de publicação e gestão de periódicos científicos. Vale destacar que o OJS é um open source software, desenvolvido no âmbito do PKP. O Public Knowledge Project foi fundado em 1998 do canadiano John Willinsky na Faculdade de Educação da University of British Columbia (UBC) com a Pacific Press Professorship, tornando-se numa iniciativa multi-universitária dedicada à promoção das produções científicas académicas.

O que motiva as universidades a adotarem plataformas digitais para exposição de sua biblioteca e produções científicas? Uma das principais razões pode ser a resposta natural ao

1 Cf. Public Knowledge Project (PKP) - URL: $<$ https://pkp.sfu.ca $>$ 
cenário global de popularização dos ambientes virtuais, o qual tem voltado cada vez mais as instituições para o espaço digital. Este contexto tem influenciado tão profundamente o comportamento estratégico das instituições que a transição das atividades para o universo digital enquadra-se no uso de uma nova linguagem planetária. Como referem Lipovetsky e Serroy:

A partir de uma nova linguagem planetária - a linguagem digital - pôs-se em marcha toda uma nova tecnologia, cuja incrível e inelutável progressão o século XXI, que há pouco se iniciou, está a descobrir em cada ano e até em cada mês. (LIPOVETSKY \& SERROY, 2010, p.95)

Podemos questionar se esta aceleração do desejo de exposição de sua produção científica, por parte das Universidades não reflete de certo modo uma vertente mais voltada ao marketing das instituições. Muitas universidades possuem Bibliotecas Digitais com seus periódicos científicos, vinculados às suas Faculdades e Centros de Investigação e não se pode negar que uma visibilidade de sua produção científica pode influenciar positivamente a prospecção de financiamentos para projetos. Como refere Philip Kotler (2013, p.13), "As universidades fazem concorrência para atrair alunos; os museus tentam atrair visitantes; as organizações teatrais procuram alargar as audiências; as igrejas procuram fiéis; e todas procuram financiamentos". Estariam os repositórios sendo utilizados dentro de uma lógica predominantemente voltada para o marketing das instituições, à promoção da imagem das das universidades? Este seria um tema interessante a investigar e que certamente provocaria calorosos debates, mas não podemos partir do pressuposto de que os repositórios digitais servem tão somente ao objetivo promocional mercadológico.

\section{Oportunidades e desafios na gestão dos repositórios digitais}

\section{1. Ética e qualidade}

Se os repositórios servem a uma maior democratização do conhecimento, com efetiva divulgação da produção científica numa escala global, a qualidade dos trabalhos que se encontram nos mais diversos repositórios digitais ainda é um assunto que se põe à mesa. A exposição dos trabalhos académicos coloca o investigador em exposição às críticas de seus pares. Aspectos relacionados à norma ou ao estilo, metodologias e mesmo questões éticas (ou criminosas) como no caso do plágio ou manipulação de resultados. Em alguns casos o investigador pode revelar dificuldades em construir um discurso articulando as fontes que têm disponíveis. Alves e Moura (2016, p.78) desenvolveram uma investigação acerca da autoria x plágio na universidade e detectaram que a escrita académica ainda demasiado deficiente no meio académico, nomeadamente da Licenciatura. Referem que "Percebe-se na escrita dos graduandos uma dificuldade em dialogar com as vozes e 
os discursos do outro, bem como situar-se como autor do próprio discurso" (ALVES $\&$ MOURA, 2016, p.178). Seria a dificuldade de escrita um problema inerente apenas ao cenário da Licenciatura? Poderíamos nos confrontar com semelhante problema no contexto de Dissertações de Mestrado ou Teses de Doutoramento? Os trabalhos acadêmicos podem refletir fragilidades que transcendem estes aspectos e que são igualmente graves. O encurtamento do tempo da Licenciatura e entrada (quase automática) do licenciado no âmbito do Mestrado pode ter afetado em alguns casos a maturidade científica dos alunos? Estas e outras questões provocam uma reflexão sobre a relação direta entre a qualidade do ensino/aprendizagem e a produção científica. Algo que não iremos aqui avançar por não ser o ponto fulcral deste artigo. Importa dizer que o Processo de Bolonha no Ensino Superior ${ }^{2}$, iniciado em Portugal em 2007 e o qual foi sujeito a inúmeras críticas em seu percurso de implantação, trouxe desafios que ainda não foram de todo superados.

Embora a responsabilidade pelo conteúdo do trabalho seja dos autores, a instituição que o armazena em seu repositório pode ver-se num dilema ético, confrontando a quantidade com a qualidade. Uma crise dos repositórios digitais académicos já se fez sentir na América Latina, na Europa e nos Estados Unidos, construindo uma imagem (nem sempre verdadeira) de que os repositórios abertos de universidades são os que apresentam qualidades e os demais são duvidosos. As publicações podem ou não estar sujeitas à um escrutínio que preserve um nível minimamente aceitável de qualidade e ética, não predominando o interesse (comercial ou académico) na aceitação de uma publicação. Não podemos ignorar o cenário atual onde diversas plataformas de repositório digital são propriedade comercial de gigantescas corporações que atuam no mercado dos periódicos científicos levando as universidades a investirem milhares de euros nas assinaturas de acesso aos periódicos em benefício da comunidade académica. Mas será que é de facto necessário este investimento? É facto que nas revistas de acesso aberto a possibilidade de falhas na qualidade de um artigo aceito pode ser maior que nas revistas de acesso restrito. Uma notícia publicada no Jornal O Público em 2013 refere a investigação do jornalista John Bohannon, da Universidade de Harvard, sobre o um caso em que 157 revistas científicas de acesso livre da área médica e afins aceitaram a publicação de um artigo relacionado à uma descoberta assinada por um cientista fictício de uma universidade fictícia (PÚBLICO, 2013). No entanto, não podemos generalizar e afirmar que todas as revistas científicas de acesso livre são frágeis em qualidade, pois mesmo as mais bem reputadas não estão livres de uma imagem negativa, resultado de falha na avaliação dos artigos que recebe para publicação.

2 Cf. UC GE3S - Grupo de Missão para o Espaço Europeu de Ensino Superior - URL: $<$ https://www. uc.pt/ge3s/destaques/aprofundar-pbolonha-portugal/> 


\section{Visibilidade e prática da obrigatoriedade como recurso de sobrevivência dos Repositórios Digitais}

Já afirmamos que os repositórios digitais das universidades permitem uma maior visibilidade entre seus pares num contexto científico global. Convém destacar ainda que a própria expectativa de visibilidade se desenvolve sentido duplo: verticalmente (Instituição - Investigador - Instituição) e horizontalmente (Investigador Interno - Investigador Externo -Investigador Interno). Neste contexto, não somente a instituição, mas também os autores e toda a produção científica armazenada goza (direta ou indiretamente) do mesmo benefício (Rico Pérez \& Montesi, 2013, p. 124).

A visibilidade converteu-se num atrativo que teoricamente provoca a tentação de fazer parte do conjunto, pois ter o trabalho em um repositório digital prestigiado com acesso livre e pode converter-se numa maior exposição. A entrada das bibliotecas académicas nas plataformas online, nomeadamente nas plataformas ao estilo Open Access, internacionalizou os trabalhos académicos, permitiu um intercâmbio global de conhecimentos e alavancou a revolução das Digital Libraries.

Segundo o Ranking Web of World Repositories, atualmente há mais de 2.000 repositórios digitais associados às instituições de investigação, 801 na Europa e o Estudo Geral Repositório Digital da Universidade de Coimbra ocupa o quinto lugar em acessos no ranking europeu (RWR, 2017). Atualmente o Estudo Geral possui 343.914 downloads mensais, um indicativo de sua relevância na comunidade académica interna e externa à UC (SIB-UC, 2017).

O sucesso dos repositórios é incontestável no cenário académico, mas um dos principais desafios enfrentados pelas instituições reside no abastecimento de seus repositórios. Embora os repositórios digitais das universidades possuam a capacidade de aumentar a visibilidade dos autores e suas investigações, a resistência em disponibilizar o trabalho no repositório da instituição ainda é uma constante. Sem depósitos suficientes a própria existência do repositório digital perde o sentido. A Universidade de Southampton (UK) viu-se obrigada a fazer uso em 2004 de uma política de depósito obrigatório dos trabalhos produzidos pelos seus investigadores e sem esta diretiva teria seu repositório abaixo do volume expectável de trabalhos (Swan \& Carr, 2008, p. 32). No caso Português, a obrigatoriedade partiu para uma esfera nacional. O Decreto-Lei $N^{\circ} 115 / 2013$ explicita que as Teses de Doutoramento e Dissertações de Mestrado "ficam sujeitas ao depósito obrigatório de uma cópia digital num repositório integrante da rede do Repositório Científico de Acesso Aberto de Portugal", refere ainda que "O depósito visa o tratamento e a preservação dos referidos trabalhos científicos, bem como a difusão, em regime de acesso aberto, da produção que não objeto de restrições ou embargos" (DR-07.08.2013).

3 Usamos a expressão "Teses de Doutoramento e Dissertações de Mestrado" em concordância com o texto do Decreto-Lei. Contudo, embora em alguns trabalhos seja possível encontrar a expressão "Teses de Mestrado ou Doutoramento". [NA] 
Até o ano de 2013 os mestrandos ou doutorandos de universidades portuguesas poderiam decidir por não permitir acesso integral ao seu trabalho, muito embora cumprisse a exigência de depositar na biblioteca em suporte de papel com a devida cópia à Biblioteca Nacional de Portugal ${ }^{4}$. Sem prejuízo aos direitos de autoria, o Decreto Lei N ${ }^{\circ}$ 151/2013 todos os trabalhos devem tornar-se públicos, algo que foi reforçado em 2015 com a Portaria $\mathrm{N}^{\circ} 285 / 2015$ de 15 de setembro (DR-15.09.2015). A portaria trouxe um maior detalhamento à legislação de 2013, estabelecendo diretrizes para garantir a acessibilidade, legibilidade e integridade dos documentos depositados, de modo a proteger sua utilização a longo-prazo (RCAAP, 2016). A legislação do Ministério da Educação e Ciência reflete o interesse governamental ${ }^{5}$ na promoção dos repositórios digitais das instituições portuguesas e promove o repositório nacional RCAAP como um agregador dos conteúdos dos diversos repositórios espalhados pelo país. Assim, podemos concluir que um levantamento feito num repositório que já esteja em plena conexão com o RCAAP, como é o caso do Estudo Geral da UC, deverá apresentar resultados espelhados no RCAAP. Em outras palavras, o que encontrarmos ou não encontramos numa consulta feita ao Estudo Geral, deve repetir-se no resultado no RCAAP. Considerando esta premissa, podemos afirmar que é possível observar as tendências de escolha de temas de Dissertações de Mestrado e Teses de Doutoramento das universidades portuguesas a partir do RCAAP.

Podemos observar a frequência de um tema no Estudo Geral da UC e no RCAAP? $\mathrm{O}$ resultado poderia refletir o interesse acadêmico/desinteresse académico por um tema para Dissertações de Mestrado e Teses de Doutoramento? O resultado de um levantamento deste tipo pode trazer á superfície um outro problema: a falta de incentivo docente que motive a investigação sobre a temática. O que motiva um investigador iniciante? Qual a relevância do orientador neste contexto? Pierre Bourdieu (2016, p.232) afirma que "A orientação da tese é também, sem dúvida, um dos indicadores mais poderosos e mais fiáveis do poder universitário". A coleção disponível no repositório deve, ao menos em parte, refletir um contexto social académico, revelando o viés temático mais adotado pelos orientadores e orientandos, pois num volume considerável de documentos é natural que haja uma variedade de temas adotados como centrais nos trabalhos de mestrado e doutoramento.

O RCAAP possui 122.093 documentos entre Dissertações e Teses entre o ano de 2014 e 2016, em diálogo com nove repositórios digitais nacionais. O portal português permite ainda integração com repositórios brasileiros através da plataforma brasileira homóloga

4 Segundo o Decreto-Lei N 362/86 de 28 de outubro, tornou-se obrigatório o depósito legal na Biblioteca Nacional de Portugal, de todas as teses de doutoramento e dissertações de mestrado.

$5 \mathrm{Na}$ adesão de Portugal à Comunidade Económica Europeia o então Primeiro Ministro Mário Soares destacou em seu discurso: "Nas mãos dos agricultores, dos operários, dos cientistas, dos homens de cultura, dos empresários, dos quadros, dos intelectuais, dos técnicos, dos artistas e, sobretudo, dos jovens, de todos os portugueses em suma, mulheres e homens, está o futuro de Portugal (...)". (Diário de Notícias, 13.06.1985, In SANDE, 2008, p.141). Atualmente, os repositórios digitais respondem a uma matriz estratégica governamental que passa pela visibilidade de suas universidades e seus investigadores e pela produção científica de impacto internacional. 
Oasisbr $^{6}$, gerida pelo Instituto Brasileiro de Informação em Ciência e Tecnologia (IBICT) o qual está ligado a Biblioteca Digital Brasileira de Teses e Dissertações (BDBTD) ${ }^{8}$. Esta última, agrega 105 instituições, 348.802 Dissertações de Mestrado e 129.487 Teses de Doutoramento. Na totalidade de recursos o Repositório Científico de Acesso Aberto de Portugal disponibiliza acesso a 1.440 .726 documentos. Assim, uma consulta ao RCAAP pode apresentar como resultados trabalhos que têm origem em universidades portuguesas e brasileiras.

Pertinência do tema Tráfico de Pessoas

Ontem plena liberdade,

A vontade por poder... Hoje... cúm'ulo de maldade, Nem são livres pr'a morrer... (Castro Alves, Navio Negreiro, V)

Em linhas gerais, quando um tema salta aos olhos, quando ele causa um choque na sociedade, é expectável que alcance a atenção de todos por um tempo mais alargado. Contudo, o tráfico de pessoas, um dos flagelos sociais mais antigos da humanidade, ainda não atingiu este ponto de graça. Na verdade, ignoramos os erros do passado e avançamos na prática em aperfeiçoar os horrores do tráfico humano. Encontramos formas mais dissimuladas e rentáveis de fazer o que ironicamente ensinamos nas escolas como uma história "distante". Hoje, o tráfico de órgãos e o tráfico de crianças e mulheres para exploração sexual, tornou-se numa rentável comódite no comércio internacional, revelando uma face obscura da globalização. Como refere Diniz (2015, p.6) "Por sua vez, o tráfico de pessoas é um dos crimes mais rentáveis a nível mundial, supostamente apenas superado pelo tráfico de droga (UNODOC, 2009 e 2014)".

Mesmo que aceitemos nossa fragilidade em lidar com este problema que envolve vertentes económicas, políticas e mesmo históricas, sabemos lidar com esta crise social? Até ponto somos impactados por ela ao ponto de nos sentirmos impelidos a investigar o problema cientificamente? Qual a nossa capacidade de gerar interesse sobre o tema entre os investigadores que estão a desenvolver suas Dissertações de Mestrado ou Teses de Doutoramento? Importa dizer que uma primeira reflexão necessária reside na devida caracterização do problema, tomando o cuidado de não confundir pela simplificação etimológica, tráfico com tráfico de pessoas. Muito embora estes dois problemas sociais caminhem

6 Cf. Oasisbr - Portal brasileiro de publicações científicas de acesso aberto - URL: $<$ http://oasisbr. ibict.br/vufind/>

7 Cf. Instituto Brasileiro de Informação em Ciência e Tecnologia (IBICT) - URL: $<$ http://www.ibict. br/sobre-o-ibict/historico-1>

8 Cf. Biblioteca Digital Brasileira de Teses e Dissertações (BBTD) - URL: <http://bdtd.ibict.br/vufind/> 
muitas vezes juntos, as investigações científicas sobre esta problemática precisam tratar os dois problemas de forma distinta.

The question of demand is also crucial to one of the most iniquitous expressions of the 'dark side of globalization': the trafficking of women and children for sexual exploration. Trafficking and human smuggling are two of very different activities, even if they are often confused or not used interchangeably by the media and politicians. (CARR, 2015, p.183)

O tráfico humano é caracterizado como um crime que ultrapassa as fronteiras nacionais com impactos igualmente alargados, amplificado especialmente nos contextos migratórios. Como destaca Kumar (2013, p.116) "Human trafficking is a transnational organized crime (TOC) associated with a cross-border human migration". Contudo, não podemos afirmar que um o tráfico humano é tão somente consequência dos fluxos migratórios em contextos de guerra ou graves crises económicas. A definição globalmente aceita considera como variáveis envolventes o recrutamento de pessoas para execução do tráfico, o rapto, o transporte e/ou transferência, o alojamento ou mesmo o acolhimento dissimulado ou por coação, a fraude e/ou engano e o abuso de poder diante da vulnerabilidade da vítima (DINIZ, 2015, p.14).

Os mais vulneráveis são sempre as primeiras vítimas dessas tragédias humanas e, neste caso em particular, o número de crianças vitimadas pelo tráfico de pessoas tem aumentado significativamente. Somente na União Europeia uma criança é dada como desaparecida a cada dois minutos, segundo o relatório de 2016 do Programa Missing Children Europe-Figures and Trends 2016. From hotlines for missing children and cross-border Family mediators. ${ }^{9}$ É interessante notar que mesmo números tão expressivos como estes não são suficientes para atrair a atenção dos media. No que refere ao tráfico de pessoas a situação complica-se ainda mais, pois a limitação em identificar o número real de vítimas revela este crime como um dos mais opacos (MARTO, 2016, p.14).

$\mathrm{O}$ aumento do número de refugiados nas fronteiras europeias tornou vulnerável mais pessoas frente ao risco de serem traficadas, em especial as crianças e mulheres. Vale lembrar que a crise humanitária dos refugiados atingiu seu ápice mediático em setembro de 2015, com a publicitação global do corpo da criança síria, Aylan Kurdi, numa praia da Turquia. Tornou-se num evento mediático, com grande impacto enquanto foi globalmente noticiado, mas logo depois caiu em esquecimento nas notícias, parecendo um facto distante e isolado no tempo. Como referem Lipovetsky \& Serroy, em a Sociedade do Ecrã Global (2010, p.250), "Este é um mundo desdobrado, onde o acontecimento se torna espetáculo".

9 Cf. Relatório 2016 do Missing Children Europe - URL: $<$ http://missingchildreneurope.eu/Portals/0/ Docs/Annual\%20and\%20Data\%20reports/Missing\%20Children\%20Europe\%20figures\%20and\%20trends\%202016.pdf> 
Logo que chega ao fim o tempo do espetáculo é preciso ter novas notícias para ocupar o mesmo espaço e captar a atenção de todos, ou quase como unir a todos num evento, por mais drmático que ele seja. Como refere Guy Debord em La Société du Spectacle, "Le spectacle se presente à la fois comme la société même, comme une partie de la société, et comme instrument d'unification. Em tant que partir de la société, il est expressément le secteur qui concentre tout regard et toute conscience" (1992, p.10).

Cabe aqui uma reflexão sobre a nossa capacidade de lidar com estas flutuações que circulam de um extremo (superexposição) a outro (esquecimento), por vezes como um modismo que nos envolve. Mas, qual o impacto desta atenção mediática sobre a forma como vemos os problemas modernos? Seria este fenómeno capaz de influenciar os interesses dos jovens investigadores e ter consequências diretas sobre a escolha das temáticas centrais de investigação de Dissertações de Mestrado ou Teses de Doutoramento? Desejamos crer que o espaço académico movimente-se numa órbita diferente, mas silenciosamente compactuamos com a visão Deleuziana de que o acontecimento é um fruto efémero, um modismo. Nas palavras de François Zourabichvili (2016, p.47) “O problema moderno, do qual o pensamento do fim é de algum modo a leitura derivada, o reflexo negativo, consiste em que já fomos tragados por outra coisa, por outros signos”. Partindo deste princípio, podemos supor que os temas flutuam de formas distintas, impulsionados pela força de influência dos momentos e seus contextos.

Com a velocidade da informação no ambiente digital e a disponibilidade de acesso à diversas plataformas que disponibilizam vídeos, notícias, artigos de jornais, periódicos científicos e livros, a pertinência de um tema pode ser observada a partir de motores de busca como o Google (ainda que superficialmente). Numa busca simples feita no Google com a palavra Human Trafficking (sem qualquer filtro), encontramos cerca de 29.700.000 resultados. Destes, cerca de 1.210.000 são notícias associadas ao tema, 1.560 .000 são vídeos e 348.000 são livros. Se repetirmos o mesmo procedimento com a palavra tráfico de seres humanos, encontramos cerca de 489.000 resultados, com a palavra tráfico de pessoas este número oscila para 495.000. Deste último, cerca de 339.000 resultados estão na categoria notícias e 53.600 resultados são livros publicados em língua portuguesa. Embora este levantamento não possa ser considerado plenamente como um resultado estatístico $100 \%$ fiável, permite-nos um panorama geral do que podemos encontrar sobre tráfico de pessoas nos motores de busca online. Importa destacar que os resultados tendem a serem mais abrangentes quando utilizamos a expressão em língua inglesa. Por outro lado, não é pequeno o resultado das buscas com expressões em língua portuguesa.

A temática do tráfico de pessoas é significativamente presente nos círculos acadêmicos, com diversos eventos nacionais e internacionais e consequente dinâmica de troca de impressões sobre esta problemática entre pares. Contudo, ainda não suficiente para preencher as lacunas no conhecimento empírico sobre o tema, provocando visões estereotipadas ou mesmo superficiais que são maiores ou menores consoante o país. Como é 
referido num artigo sobre o trafico de pessoas na República Democrática do Laos, "The apparent disconnect between human trafficking as discourse and its empirical knowledge base raises a number of pressing questions" (HUIJSMANS, 2011, p.67). Uma das lacunas anteriormente citada, refere quanto à inclusão da análise da problemática do tráfico humano entre outras como o tráfico de drogas e as migrações. É importante destacar que não é o objetivo deste artigo desenvolver críticas quanto às produções científicas, mas sim, apontar determinados aspectos que sirvam de suporte aos argumentos que estamos desenvolvendo. Neste caso em particular, basta-nos provocar a reflexão quanto à combinação das problemáticas já referidas num mesmo discurso. Embora sejam temáticas distintas com suas devidas complexidades, não é incomum encontrarmos trabalhos que associam estes temas num mesmo conjunto dificultando as pesquisas quanto à frequência do tema "tráfico de pessoas" nos repositórios digitais. Localizamos na plataforma B-On um interessante artigo publicado em 2010 que serve de exemplo à nossa reflexão. Intitulado "Migración, secuestro, trata y tráfico de personas (Esclavitud del siglo XXI)", a autora do artigo traz uma rica análise acerca da migração económica no México enquanto fenómeno sociológico, discorrendo sobre seus desdobramentos e vitimização das mulheres. No entanto, na complexidade dos elementos associados abordados no discurso, o problema do tráfico de pessoas não consegue ganhar o devido protagonismo. O que compreendemos quando o vemos inserido na reflexão acerca da vitimização da mulher nos contextos migratórios. Não é que os trabalhos científicos deixam de investigar sobre o tráfico de pessoas, não afirmamos isso. O que falta muitas vezes é focalizar no discurso o problema, sem prejuízo aos desdobramentos e às vítimas deste flagelo social. Então, temos um desafio imposto aos investigadores: Como tratar a relação entre estes temas, sem tratá-los em conjunto? Ou ainda, como tratar o tema tráfico de pessoas sem secundarizá-lo, mesmo que seja abordado em conjunto com outros temas associados?

Importa lembrar que estamos a lidar com uma expressão cuja flexibilidade de abordagens $^{10}$ é um elemento que permite certa elasticidade, tocando diversas áreas do conhecimento como o Direito, a Psicologia, a Sociologia, as Ciências Políticas, a Educação entre outras. Isso pode trabalhar em favor do aumento de investigações em torno do tema, dependendo do grau de interesse dos professores em orientar trabalhos que estejam cingidos no tema do tráfico de pessoas. Mas como já referimos repetidas vezes, é preciso acautelarmo-nos quanto ao deslocamento do problema central para a periferia do discurso.

\section{Metodologia}

A definição de uma metodologia clara e objetiva permite o desenvolvimento de uma investigação com maiores chances de atingir seus objetivos. Os deslizes de percurso podem sempre

10 São muitas as expressões adotadas, entre elas: tráfico de pessoas, tráfico humano, tráfico internacional de pessoas, tráfico de mulheres, traffic of people, human trafficking. 
surgir por diversas razões, mas é na metodologia que se agarra o investigador para melhor compreender os resultados alcançados. Quivy e Campenhoudt (2013, p.19) referem que na melhor das hipóteses o investigador tem a possibilidade de "compreender melhor os significados de um acontecimento ou de uma conduta, a fazer inteligentemente o ponto da situação".

Para o desenvolvimento deste artigo foi definido como objeto de investigação "a frequência de Dissertações de Mestrado e Teses de Doutoramento no Estudo Geral da UC". A delimitação temporal foi definida como o período compreendido entre 2006 e 2016, enquanto que o Estudo Geral, repositório digital da UC, foi a delimitação física da investigação (virtual). Importa destacar que todo o trabalho foi feito utilizando os mesmos caminhos que um investigador externo adotaria para aceder aos recursos do repositório digital da UC, cujo objetivo central é guardar, gerir e partilhar a produção científica de seus investigadores.

Este artigo trouxe respostas às seguintes perguntas de investigação: 1. Qual a frequência do tema "Tráfico de Pessoas" em Dissertações de Mestrado e Teses de Doutoramento depositadas no Estudo Geral da UC entre 2006 e 2016?; 2. O que é possível inferir acerca do interesse científico pelo tema a partir das frequências de Dissertações de Mestrado e Teses de Doutoramento depositadas no Estudo Geral?

O objetivo geral foi verificar a frequência do tema "Tráfico de Pessoas" em Dissertações de Mestrado e Teses de Doutoramento depositadas no Estudo Geral da UC entre 2006 e 2016 e refletir sobre o interesse dos investigadores pelo tema. Para suportar este objetivo central, foram definidos como objetivos específicos:

- Contextualizar o cenário dos repositórios digitais, discorrendo acerca das oportunidades e desafios;

- Apresentar, em linhas gerais, o Estudo Geral (repositório digital da UC), bem como discorrer acerca das dinâmicas de partilhas no contexto nacional e internacional;

- Verificar no catálogo da Biblioteca Geral da UC - opção "coleção inteira" - quais trabalhos que não são encontrados no Estudo Geral da UC mas estão disponíveis no catálogo;

- Verificar no Repositório Científico de Acesso Aberto de Portugal (RCAAP) a frequência do tema tráfico de pessoas em Dissertações de Mestrado e Teses de Doutoramento;

- Identificar alguns aspectos que podem influenciar positivamente ou negativamente o interesse dos investigadores em explorar o tema tráfico de pessoas enquanto objeto de investigação em suas Dissertações de Mestrado ou Teses de Doutoramento.

Neste estudo, foi adotada uma abordagem quantitativa quanto ao tipo/método, explicativa quanto aos objetivos e descritiva quanto aos procedimentos. O Estudo Geral, repositório digital da Universidade de Coimbra e o Repositório Científico de Acesso Aberto de Portugal (RCAAP) foram as fontes utilizadas para o levantamento dos dados. A consulta ao RCAAP justifica-se pelo facto de que todos os repositórios portugueses são obrigados a estarem em conexão/diálogo com o repositório nacional. 


\section{Resultados}

Neste ano de 2017 o Estudo Geral está a passar por algumas atualizações e ajustes na sua plataforma, a qual terminou por mudar a forma de acesso e exibição de resultados de busca. Para verificar se houve severas mudanças/atualizações nos dados coletados em 2016 (Out2016), em 06 de junho de 2017 foi feita uma nova pesquisa (Jun2017), comparada com a anterior e servindo-nos a referência de dados dos dois períodos distintos. Na altura da apresentação da comunicação que gerou este artigo - 18 de outubro de 2016, A pesquisa feita no Estudo Geral - repositório digital da Universidade de Coimbra (Out2016), apresentava 18.614 documentos ${ }^{11}$ depositados no período compreendido entre os anos de 2006 e 2016. Deste total, 7.005 documentos eram Dissertações de Mestrado (DM) e 3.425 eram Teses de Doutoramento (TD).

No entanto, ao realizar a pesquisa com por "tráfico de pessoas" (Tabela 1) em todo o repositório, foram encontrados três resultados. Isso significa que $0,04 \%$ do total de DM (7.005) depositadas, ou $0,01 \%$ deste total, tinham como tema central o tráfico de pessoas. Importa ainda destacar que deste total, apenas uma DM é localizável na pesquisa no Estudo Geral e duas outras surgem disponíveis no catálogo da Biblioteca Geral da Universidade de Coimbra (BGUC) - opção “coleção inteira”. Não foram encontradas Teses de Doutoramento.

Tabela 1 - Pesquisa por «Tráfico de Pessoas» - Out2016

\begin{tabular}{|c|c|c|c|c|}
\hline Tipo doc. & Ano & Biblioteca & Título & Autor \\
\hline $\begin{array}{c}\text { Dissertação de } \\
\text { Mestrado }\end{array}$ & 2010 & UC CES & $\begin{array}{c}\text { Direitos Humanos, tráfico de pessoas e } \\
\text { exploração sexual de mulheres, em Belém - } \\
\text { Pará - Brasil }\end{array}$ & Smith, A. S. P. O.* \\
\hline $\begin{array}{c}\text { Dissertação de } \\
\text { Mestrado }\end{array}$ & 2010 & FDUC & $\begin{array}{c}\text { O crime de tráfico de seres humanos: evolu- } \\
\text { ção e diferenciações }\end{array}$ & Pedro, N. F.* \\
\hline $\begin{array}{c}\text { Dissertação de } \\
\text { Mestrado }\end{array}$ & 2015 & FDUC & $\begin{array}{c}\text { O crime de tráfico de pessoas para explo- } \\
\text { ração sexual: uma análise legislativa luso- } \\
\text {-brasileira }\end{array}$ & $\begin{array}{c}\text { Moreno, C. M. } \\
\text { M. P. }\end{array}$ \\
\hline
\end{tabular}

*Esta entrada somente aparece quando consultamos o catálogo da BGUC - opção coleção inteira

Na pesquisa Jun2017 (Tabela 2), o Estudo Geral apresentava um total de 28.587 documentos depositados, 23.441 em acesso aberto e 343.914 downloads mensais. Ao pesquisar por "tráfico de pessoas", em todo o repositório, foram encontrados apenas 06 resultados. Deste total, havia 1 artigo, 03 DM disponíveis no Estudo Geral e 02 DM no catálogo da BGUC. Mais uma vez, o resultado não indicou TD. Observa-se que houve um aumento total de quase 10.000 documentos depositados, para o aumento de apenas 02 DM voltadas para o tema tráfico de pessoas.

11 Convém explicar que a expressão documento, neste contexto, representa o conjunto de literatura depositada (livros, artigos, dissertações de mestrado e teses de doutoramento.) 
Tabela 2 - Pesquisa por "Tráfico de Pessoas" - Jun2017

\begin{tabular}{|c|c|c|c|c|}
\hline Tipo doc. & Ano & Biblioteca & Título & Autor \\
\hline $\begin{array}{c}\text { Dissertação de } \\
\text { Mestrado }\end{array}$ & 2010 & UC CES & $\begin{array}{c}\text { Direitos Humanos, tráfico de pessoas e } \\
\text { exploração sexual de mulheres, em Belém - } \\
\text { Pará - Brasil }\end{array}$ & Smith, A. S. P. O.* \\
\hline $\begin{array}{c}\text { Dissertação de } \\
\text { Mestrado }\end{array}$ & 2010 & FDUC & $\begin{array}{c}\text { O crime de tráfico de seres humanos: evolu- } \\
\text { ção e diferenciações }\end{array}$ & Pedro, N. F.* \\
\hline $\begin{array}{c}\text { Dissertação de } \\
\text { Mestrado }\end{array}$ & 2015 & FDUC & $\begin{array}{c}\text { O crime de tráfico de pessoas para explo- } \\
\text { ração sexual: uma análise legislativa luso- } \\
\text {-brasileira }\end{array}$ & Moreno, C. M. M. P. \\
\hline $\begin{array}{c}\text { Dissertação de } \\
\text { Mestrado }\end{array}$ & 2015 & FDUC & $\begin{array}{c}\text { O Crime de Tráfico de Pessoas. Contextuali- } \\
\text { zação da legislação nacional e internacional, } \\
\text { análise do crime e comparação face a crimes } \\
\text { conexos }\end{array}$ & Gameiro, J. D. N. \\
\hline $\begin{array}{c}\text { Dissertação de } \\
\text { Mestrado }\end{array}$ & 2016 & FMUC & $\begin{array}{c}\text { Tráfico de seres humanos: uma perspectiva } \\
\text { geral sobre a exploração sexual de mulheres }\end{array}$ & Fernandes, V. L. S. \\
\hline
\end{tabular}

*Esta entrada somente aparece quando consultamos o catálogo da BGUC - opção coleção inteira

Considerando que o repositório digital da UC mantém o depósito obrigatório de todas das Dissertações de Mestrado e Teses de Doutoramento, em diálogo com o catálogo da Biblioteca Geral da UC, decidiu-se por verificar o a frequência do tema no catálogo, especialmente de DM e TD. Abaixo, na Tabela 3, podemos verificar que os resultados são semelhantes aos que encontramos no Estudo Geral. Mesmo quando pesquisamos em outras coleções da BGUC.

Tabela 3 - Out2016 - Pesquisa no Catálogo da BGUC

\begin{tabular}{|c|c|c|c|c|}
\hline Palavra/Expressão & Coleção & Resultados & Quant./Tipo & Detalhes \\
\hline \multirow{10}{*}{ Tráfico de Pessoas } & $\begin{array}{c}\text { Coleção Inteira da } \\
\text { BGUC }\end{array}$ & 144 & - & - \\
\hline & \multirow{5}{*}{$\begin{array}{l}\text { Teses e produção Cientí- } \\
\text { fica da UC }\end{array}$} & \multirow{5}{*}{13} & $03 \mathrm{DM}$ & Fernandes, 2016 \\
\hline & & & $02 \mathrm{DM}$ & Moreno, 2015 \\
\hline & & & $01 \mathrm{DM}$ & Pedro, 2010* \\
\hline & & & 07 Artigos & - \\
\hline & & & $0 \mathrm{TD}$ & - \\
\hline & \multirow{3}{*}{ Teses da UC } & \multirow{3}{*}{06} & $03 \mathrm{DM}$ & Fernandes, 2016 \\
\hline & & & $02 \mathrm{DM}$ & Moreno, 2015 \\
\hline & & & $01 \mathrm{DM}$ & Pedro, 2010* \\
\hline & Teses & 01 & $01 \mathrm{DM}$ & Smith, 2010* \\
\hline
\end{tabular}

* As Dissertações de Mestrado de Smith, 2010 e Pedro, 2010, embora estejam depositadas e devidamente inseridas no catálogo, não aparecem quando é feita a pesquisa via Estudo Geral.

As pesquisas Out2016 e Jun2017 consideram ainda as expressões "tráfico de pessoas, tráfico humano, tráfico internacional de pessoas, tráfico de mulheres, traffic of people, human trafficking" nas consultas ao repositório da UC (Tabela 4). 
Tabela 4 - Resultados das Pesquisas Out2016 e Jun2017

\begin{tabular}{|c|c|c|c|c|}
\hline Palavra & Pesq. & Result. & Tipo Doc & $\begin{array}{c}\text { Autores / Ano / Biblio- } \\
\text { teca }\end{array}$ \\
\hline \multirow[t]{8}{*}{ Tráfico de Pessoas } & Out2016 & 03 & Dissertações de Mestrado & Smith, 2010, CES* \\
\hline & & & & Pedro, 2010, FDUC* \\
\hline & & & & Moreno, 2015, FDUC \\
\hline & Jun2017 & 05 & Dissertação de Mestrado & Smith, 2010*, CES \\
\hline & & & & Pedro, 2010*, FDUC \\
\hline & & & & Moreno, 2015, FDUC \\
\hline & & & & Gameiro, 2015, FDUC \\
\hline & & & & $\begin{array}{c}\text { Fernandes, 2016, } \\
\text { FMUC }\end{array}$ \\
\hline \multirow[t]{2}{*}{ Traffic of People } & Out2016 & 0 & - & - \\
\hline & Jun2017 & 0 & - & - \\
\hline \multirow[t]{2}{*}{ Tráfico Internacional } & Out2016 & 0 & - & - \\
\hline & Jun2017 & 0 & - & - \\
\hline \multirow[t]{2}{*}{ Tráfico Humano } & Out2016 & 0 & - & - \\
\hline & Jun2017 & 1 & Dissertação de Mestrado & $\begin{array}{l}\text { Fernandes, 2016, } \\
\text { FMUC }\end{array}$ \\
\hline \multirow[t]{2}{*}{ Human Traffic } & Out2016 & 0 & - & - \\
\hline & Jun2017 & 1 & Dissertação de Mestrado & $\begin{array}{c}\text { Fernandes, 2016, } \\
\text { FMUC }\end{array}$ \\
\hline \multirow[t]{2}{*}{ Human Trafficking } & Out2016 & 0 & - & - \\
\hline & Jun2017 & $\begin{array}{l}1 \\
1\end{array}$ & $\begin{array}{c}\text { Dissertação de Mestrado } \\
\text { Artigo (2 cópias/versões PT/EN) }\end{array}$ & $\begin{array}{l}\text { Fernandes, 2016, } \\
\text { FMUC } \\
\text { Santos, 2016, CES }\end{array}$ \\
\hline \multirow[t]{2}{*}{ Tráfico de Mulheres } & Out2016 & 1 & Dissertação de Mestrado & Smith, 2010, CES* \\
\hline & Jun2017 & 2 & Dissertação de Mestrado & $\begin{array}{l}\text { Fernandes, 2016, } \\
\text { FMUC } \\
\text { Smith, 2010, CES* }\end{array}$ \\
\hline
\end{tabular}

*Esta entrada somente aparece quando consultamos o catálogo da BGUC - opção coleção inteira

Como nenhuma Tese de Doutoramento foi encontrada nas pesquisas feitas com as diferentes expressões de busca ${ }^{12}$, foi feita uma pesquisa no catálogo da BGUC, com a opção "ver coleção inteira" "qualquer campo" para verificar o volume de entradas gerais com as mesmas palavras da Tabela 4. O objetivo deste levantamento foi obter o resultado generalizado, o que permitiu uma visão global do que há disponível ao investigador que acede a plataforma da UC sobre o tema do tráfico de pessoas.

12 Palavras/expressões utilizadas na pesquisa: palavras tráfico de pessoas, traffic of people, tráfico internacional de pessoas, tráfico humano, human traffic, human trafficking e tráfico de mulheres 
Entre os 144 resultados para a expressão Tráfico de Pessoas estão as Dissertações de Mestrado anteriormente encontradas. A expressão Traffic of People gerou apenas um resultado e este refere-se a Geografia Social e doenças infecto-contagiosas.

Para a expressão Tráfico Humano há 03 resultados e nenhum deles é alguma das Dissertações já encontradas. Com a expressão Human Traffic, foram gerados 06 resultados, dos quais apenas um refere-se à vitimização da mulher e outros cinco ao tráfico rodoviário. O resultado é bem mais interessante quando utilizamos a expressão Human Trafficking, onde obtemos 29 resultados e todos relacionados ao tema.

Com a expressão Tráfico de Pessoas foram encontrados 31 resultados e todos relacionados ao tema, incluindo as Dissertações de Mestrado anteriormente encontradas. A expressão Tráfico de Mulheres gerou 66 resultados, sendo quatro deles diretamente relacionados ao tráfico de drogas e um deles com registo indisponível.

Do universo de 144 entradas apenas 05 são Dissertações de Mestrado e não foi localizada nenhuma Tese de Doutoramento. Para verificar se algum resultado referente às Dissertações de Mestrado e Teses de Doutoramento por alguma razão não foi localizado, foi feito semelhante procedimento de pesquisa no RCCAP, uma vez que o repositório digital da UC possui ligação com o RCAAP. O procedimento de pesquisa feita no RCAAP em Out2016 foi apenas pela expressão Tráfico de Pessoas (Tabela 5) no intervalo temporal de 2006 e 2016. Ao repetir o procedimento de Out2016, a pesquisa Jun2017 pode verificar se houve alterações nos resultados antes obtidos.

Tabela 5 - Pesquisa por "Tráfico de Pessoas" - RCAAP - Out2016 / Jun2917

\begin{tabular}{|c|c|c|c|}
\hline Pesquisa & Quant. & Tipo Doc. & Respositório de Origem \\
\hline Out2016 & 19 & $\begin{array}{l}02-\text { Artigos } \\
08-\mathrm{DM} \\
09-\mathrm{DL} \\
0-\mathrm{TD}\end{array}$ & $\begin{array}{l}16 \text { - OASISbr } \\
01 \text { - Repositório da Universidade de Lisboa } \\
01 \text { - Repositório da Universidade do Minho } \\
01 \text { - Estudo Geral da UC }\end{array}$ \\
\hline Jun2017 & 42 & $\begin{array}{l}02 \text { - Outros } \\
14 \text { - Artigos } \\
08 \text { - DL } \\
15 \text { - DM } \\
01 \text { - TD }\end{array}$ & $\begin{array}{l}30 \text { - OASISbr } \\
02 \text { - ISCTE-IUL } \\
02 \text { - Repositório Comum } \\
01 \text { - Repositório Institucional de Aveiro } \\
01 \text { - Repositório Institucional da UNL } \\
01 \text { - Repositório da Universidade de Lisboa } \\
01 \text { - Repositório da Universidade do Minho } \\
04 \text { - Estudo Geral da UC }\end{array}$ \\
\hline
\end{tabular}

*Esta entrada somente aparece quando consultamos o catálogo da BGUC - opção coleção inteira 
Verificamos que o resultado duplica em relação ao ano anterior, subindo de 19 para 42 entradas. Na distribuição por repositórios podemos ver que o Estudo Geral da UC aumenta sua participação nos resultados com um salto de 01 para 04 resultados. $\mathrm{O}$ gráfico 2 permite uma visão comparativa entre os resultados de 2016 e 2017, onde destaca-se que surge como resultado em 2017 uma TD, bem como a quase duplicação no número de DM associadas ao tema.

\section{Conclusões}

A partir da análise dos resultados na consulta a estas fontes referidas, verificamos a frequência do tema "Tráfico de Pessoas" enquanto objeto central de Dissertações de Mestrado e Teses de Doutoramento depositadas no Estudo Geral da Universidade de Coimbra entre 2006 e 2016. Desta forma, respondemos a primeira pergunta de investigação: Qual a frequência do tema “Tráfico de Pessoas" em Teses de Mestrado ou Doutoramento depositadas no Estudo Geral da UC entre 2006 e 2016?

Para apresentar respostas possíveis à segunda pergunta de investigação, "O que é possível inferir acerca do interesse científico pelo tema a partir das frequências de Dissertações de Mestrado e Teses de Doutoramento depositadas no Estudo Geral?", procedemos uma leitura dos resultados partindo do pressuposto de que o volume de depósitos de Teses de Dissertações no Estudo Geral reflete o interesse dos jovens investigadores de Mestrado ou Doutoramento. Por outro lado, consideramos ainda uma reflexão acerca da influência do contexto externo (frequência de trabalhos de outras instituições) e o contexto interno (orientadores engajados na temática).

Embora não seja o objeto deste estudo, é importante citar que todos os anos um conjunto de eventos relacionados com o tema do Tráfico de Pessoas é uma constante na Universidade de Coimbra. Estes eventos somente são possíveis graças ao esforço dos investigadores da UC, cujo interesse pelo tema reflete-se diretamente numa ampla rede de contatos. Esta reflexão traz-nos um paradoxo, pois estamos diante de um contexto académico que apresenta interesse pelo tema e, ao mesmo tempo, não temos tantos trabalhos sendo desenvolvidos no âmbito de Mestrado ou Doutoramento. Uma vez que apenas cinco Dissertações de Mestrado é de facto, um número muito baixo num conjunto de mais de 28.000 documentos depositados no Estudo Geral da UC.

Como este artigo foi feito a partir de uma comunicação de 2016, os dados foram atualizados segundo as informações de 2017, identificando que o repositório digital da UC apresentou um aumento de quase 10.000 documentos depositados. Por outro lado, em um ano apenas duas Dissertações de Mestrado foram acrescentadas ao repositório. Diante de resultados tão discrepantes e alarmantes, foi feita uma consulta ao catálogo geral da UC e ao RCAAP. Ainda assim, os resultados baixos permaneceram refletindo um cenário de baixa produção científica voltada ao tema do tráfico de pessoas disponível nestes repositórios. 
O RCAAP apresentou apenas 42 resultados, dos quais 30 eram do repositório brasileiro OASISbr e apenas 12 de repositórios portugueses. Destes, apenas 15 Dissertações de Mestrado e 01 Tese de Doutoramento. Isto implica em afirmar que apenas 16 investigadores escolheram empenhar seus esforços no âmbito de Mestrado ou Doutoramento, para investigar sobre o tema tráfico de pessoas. Seria este tema de tão pouco interesse para a comunidade científica? Seria a dificuldade em encontrar suporte teórico, literatura disponível, outros trabalhos? No catálogo da BGUC há 144 resultados para a expressão tráfico de pessoas, entre livros, documentos, relatórios, atas de congressos e dissertações. Embora seja um número relativamente baixo frente ao universo depositado, podemos afirmar que há material disponível e acessível. O que impede os jovens investigadores de sentirem-se motivados com o tema?

Se a relevância do tema é incontestável no discurso nos círculos académicos, a representatividade do mesmo não se reflete na produção científica. Assim, duas novas questões surgem nesta investigação: 1 . Por que há tão poucos trabalhos científicos depositados no Estudo Geral sobre o tema Tráfico de Pessoas? 2. Qual é a relevância do tema para os investigadores de mestrado ou doutoramento?

No conjunto de resultados pouco interessantes convém destacar que o RCAAP apresentou um aumento significativo no número de trabalhos relacionados ao tema, em comparação com 2016 (mais de 100\%) subindo de 19 para 42 resultados. É fundamental destacar que esta investigação se cingiu para o caso da Universidade de Coimbra, para a produção científica interna. Lançando aqui um alerta, pois um baixo volume de trabalhos de Mestrado e Doutoramento voltados ao tema é no mínimo preocupante.

Toda a investigação impõe desafios que precisam ser superados, barreiras que precisam ser ultrapassadas. No caso particular deste artigo, pelo menos três desafios sobressaem-se aos demais. O primeiro desafio consistiu em preservar ao máximo o scopo central da investigação, evitando de cometer o mesmo erro que identificamos muitas vezes: colocar o tráfico de pessoas em plano secundário frente ao tráfico em geral, às crises de migração/refugiados (ou que levam à migração) ou aos dilemas político-sociais. O segundo desafio esteve na gestão da emoção, na frustração de que todo o investigador é vítima quando não encontra resultados, ou ainda pior, quando descobre que a inexistência de resultados pode revelar uma severa fragilidade no interesse por um tema de tão grande relevância. O terceiro, e não menos complicado que os demais, está na administração da crítica e mesmo autocrítica. Incluindo-se no universo criticado, foi preciso extrair os indicativos de problemas com a cautela de não generalizar ou pelo menos colocar em dúvida a qualidade deste ou aquele trabalho.

Este artigo cumpriu seu principal e modesto objetivo, lançando reflexão à um paradoxal drama académico, num cenário onde muito se fala sobre o tráfico de pessoas e pouco se investiga no âmbito dos mestrados e doutoramentos. 


\section{Referências}

ALVES, Castro - [Em linha]. EX! Editora, 2016. [Consult. 05 Jun. 2017. Disponível na internet. <URL: http://exeditora.blogspot.pt/p/primordios-do-fantastico-brasileiro. html >. Esta obra encontra-se em domínio público no Brasil, de acordo com a Lei N9.610, art.41 de 19 de fevereiro de 1998.

ALVES, Maria Fátima \& MOURA, Lucielma de Oliveira Batista Magalhães. A escrita de artigo acadêmico na universidade: autoria x plágio / Writing a Research paper at the University: Authorship vs Plagiarism. [Em linha]. 60, 3 (2016), p. 77-93. [Consult. 04 Jun. 2017]. Disponível em WWW: URL: <http://www.scielo.br/pdf/ides/v69n3/21758026-ides-69-03-00077.pdf>. ISSN: 0099-1333>. ISSN: 2175-8026

BDBTD. . [Em linha]. bdbtd. [Consult. 04 Jun. 2017]. Disponível em WWW: URL: < http://bdtd.ibict.br/vufind/>

BOUDIEU, Pierre. . Trad. Teresa Moreira. Ramada: Edições Pedago, LDA, 2016. ISBN: 978-989-8655-56-1

CARR, Matthew. . London: Hurst \& Company, 2015. ISBN: 978-1-84904-6-275

CHEN, Hsin-liang., \& ZHANG, Yin. Functionality Analysis of an Open Source Repository System: Current Practices and Implications. [Em linha]. 40 (2014), p. 558-564. [Consult. 03 Jun. 2017]. Disponível em WWW: URL: < http://dx.doi.org/10.1016/j.acalib.2014.09.012>. ISSN: 0099-1333

DEBORD, Guy - [Em linha]. Paris: Gallimard, 1992. [Consult. 05 Jun. 2017. Disponível na internet. <URL: http://classiques.uqac.ca/contemporains/debord_guy/societe du spectacle/societe du spectacle.pdf $>$. Collection développée en collaboration avec la Bibliothèque Paul-Émile-Boulet de l'Université du Québec à Chicoutimi

DECRETO Lei N 151/13 de 07 de Agosto de 2013 do Ministério da Educação e Ciência. [Em linha]. : I série, $\mathrm{N}^{\circ} 151$ [Consult. 04 Jun. 2017]. Disponível em WWW: URL:< https://dre.pt/application/file/498425>

DEPÓSITO LEGAL DE TESES E DISSERTAÇÕES. Como auto-arquivar documentos / Teses \& Dissertações. . [Em linha]. Portugal: RCAAP. [Consult. 04 Jun. 2017]. Disponível em WWW: URL: < http://projeto.rcaap.pt/index.php/lang-pt/como-auto-arquivar-documentos/teses-a-dissertacoes $>$

DIÁRIO DE NOTÍCIAS de 13.06.1985. . In SANDE, Paulo de Almeida (Coord.). . Lisboa: Parlamento Europeu. Gabinete de Portugal, 2008. ISBN 978-972-99471-8-6

DINIZ, Ricardo Jorge da Mota Rocha - [Texto policopiado] Aveiro: [S.n], 2015. Dissertação de mestrado. [Consult. 05 Jun. 2017]. Disponível em WWW: URL: < http://ria. ua.pt/handle/10773/16430>

GALINDO, C. V. Migración, secuestro, trata y tráfico de personas. [Em linha]. 76 (2010), p. 859-876. [Consult. 05 Jun. 2017]. Disponível em WWW: URL: <http://eds.a.ebscohost. com/eds/pdfviewer/pdfviewer?sid=511de518-5e79-4156-93a8-8141b5543737\%40sessionmg r4010\&vid=3\&hid=4105>. ISSN: 16655699 
GERSCHENFELD, Ana. Falso artigo científico aceite para publicação por mais de 150 revistas de acesso livre. . [Em linha]. Público/Ciência/Notícia. [Consult. 04 Jun. 2017]. Disponível em WWW: URL: <https://www.publico.pt/2013/10/04/ciencia/noticia/falso-artigo-cientifico-aceite-para-publicacao-por-quase-200-revistas-especializadas-de-acesso-livre-1608118>

HUIJSMANS, Roy. The theatre of Human Trafficking: A global discourse on Lao stages. [Em linha]. 1, 2 (2011), p. 66-84. [Consult. 05 Jun. 2017]. Disponível em WWW: URL: $<$ https://www.jstor.org/stable/23971913?seq=1\#page_scan_tab_contents $>$. ISSN: 17570352

IBICT. . [Em linha]. ibict. [Consult. 04 Jun. 2017]. Disponível em WWW: URL: < http:// www.ibict.br/sobre-o-ibict/historico-1>

KUMAR, Sunnel. Exploring the Rural-Agrarian linkages of human trafficking: A study of the Indian Punjab. Em linha]. 51, 4 (2013), p. 116-129. [Consult. 05 Jun. 2017]. Disponível em WWW: URL: <http://eds.a.ebscohost.com/eds/pdfviewer/ pdfviewer?sid=f7816a57-b136-43ad-9e33-36748646af09\%40sessionmgr4008\&vid=0 \&hid=4105>. ISSN: 0020-7985

LIPOVETSKY, Gilles \& SERROY, Jean. . Trad. Victor Silva. Lisboa: Edições 70, 2010. ISBN: 978-972-44-1586-4

LIPOVETSKY, Gilles \& SERROY, Jean. . Trad. Luís Filipe Sarmento. Lisboa: Edições 70, 2010. ISBN: 978-972-44-1555-0

MARTO, Rita A. Gaspar - [Texto policopiado] Lisboa: [S.n], 2016. Dissertação de mestrado. [Consult. 05 Jun. 2017]. Disponível em WWW: URL: <https://run.unl.pt/handle/10362/19173>

MISSING CHILDREN EUROPE. . [Em linha]. 2016 Report. [Consult. 05 Jun. 2017]. Disponível em WWW: URL: <http://missingchildreneurope.eu/Portals/0/Docs/Annual\%20and\%20Data\%20reports/Missing\%20Children\%20Europe\%20figures\%20and\%20 trends\%202016.pdf>

OASISBR. . [Em linha]. Oasisbr. [Consult. 04 Jun. 2017]. Disponível em WWW: URL: $<$ http://oasisbr.ibict.br/vufind/>

PORTARIA N 285/15 de 15 de Setembro de 2015 do Ministério da Educação e Ciência. [Em linha]. : I série, $\mathrm{N}^{\circ} 180$ [Consult. 04 Jun. 2017]. Disponível em WWW: URL:< https://dre.pt/application/file/70297526>

PUBLIC KNOWLEDGE PROJECT. . [Em linha]. PKP. [Consult. 04 Jun. 2017]. Disponível em WWW: URL: <http:// https://pkp.sfu.ca>

QUIVY, Raymond \& CAMPENHOUDT, Luc Van. . Trad. João Minhoto Marques, Maria Amália Mendes e Maria Carvalho. Lisboa: Gradiva, 2013. ISBN: 978-972$662-275-8$

RICO PÉREZ, Yaneti Elisa., \& MONTESI, Michela. (2013). Visibilidad y uso de colecciones digitalizadas: propuesta de un indicador de visibilidad relativa. , 7 (2013). p. 123-129. [Consult. 04 Jun. 2017]. Disponível em WWW: URL: <http://www.ibersid.eu/ojs/index.php/ ibersid/article/view/4045>. ISSN: 1888-0967 
REPOSITORIES WEBOMETRICS.. [Emlinha]. RWR. [Consult. 03 Jun. 2017]. Disponível em WWW: URL: http://repositories.webometrics.info/en/world?sort=desc\&order=ranking

SERVIÇO INTEGRADO DAS BIBLIOTECAS DA UNIVERSIDADE DE COIMBRA. Repositório Digital da Produção Científica da Universidade de Coimbra. . [Em linha]. Coimbra: SIBUC. [Consult. 03 Jun. 2017]. Disponível em WWW: URL: <https://estudogeral.sib.uc.pt/?locale=pt_PT $>$

SWAN, Alma \& CARR, Leslie. Institutions, Their Repositores and the Web. [Em linha]. 34 (2008), p. 31-35. [Consult. 04 Jun. 2017]. Disponível em WWW: URL: <http:// www.tandfonline.com/doi/abs/10.1080/00987913.2008.10765149> ISSN: 1879-095X

UC DIGITALIS. . [Em linha]. UC Digitalis. [Consult. 04 Jun. 2017]. Disponível em WWW: URL: < https://digitalis.uc.pt/pt-pt/content/uc_digitalis>

UC GE3S. . [Em linha]. GE3S - Grupo de Missão para o Espaço Europeu de Ensino Superior. [Consult. 04 Jun. 2017]. Disponível em WWW: URL: < https://www.uc.pt/ge3s/ destaques/aprofundar-pbolonha-portugal/>

ZOURABICHVILI, François. . Trad. Luiz B. L. Orlandi. São Paulo: Editora 34, 2016. ISBN: 978-85-7326-625-2

Artigo Recebido a 27 de junho de 2017 | Aceite a 18 de julho de 2017 